\title{
Paquimeningite Hipertrófica e Parotidite: Manifestações Raras da Granulomatose de Wegener ${ }^{*}$
}

\section{Hypertrophic Pachymeningitis and Parotiditis: Unusual Ocurrences of the Wegener's Granulomatosis}

\author{
Ana Paula Monteiro Gomides ${ }^{(1)}$, Gustavo Lamego de Barros Costa ${ }^{(2)}$, Cáris de Rezende Pena ${ }^{(3)}$, \\ Eduardo José do Rosário( ${ }^{(4)}$, Patrícia Noronha Guimarães ${ }^{(5)}$ e Paulo Madureira de Pádua ${ }^{(6)}$
}

\section{RESUMO}

A granulomatose de Wegener é uma vasculite sistêmica dos vasos de médio e pequeno calibre. Classicamente, há formação de granulomas com necrose no trato respiratório e glomerulonefrite necrosante. Embora seu acometimento mais comum envolva o trato respiratório superior, pulmões e rins, uma vasta gama de manifestações em vários órgãos e tecidos é descrita. Relatamos o caso de um paciente que, paralelamente às manifestações típicas da doença, desenvolveu algumas alterações raras como a parotidite e a paquimeningite hipertrófica. Diante de quadros graves, atípicos e/ou refratários ao tratamento convencional, torna-se necessário o aprofundamento no estudo e uso de novas armas terapêuticas.

Palavras-chave: granulomatose de Wegener, parotidite, paquimeningite hipertrófica.

\section{INTRODUÇÃO}

A granulomatose de Wegener (GW) é uma vasculite sistêmica dos vasos de médio e pequeno calibres $^{(1)}$ que, embora ainda de etiologia desconhecida, está associada aos anticorpos anticitoplasma de neutrófilos (ANCA), especialmente contra a proteinase 3 (cANCA) ${ }^{(2)}$.

Envolve igualmente ambos os sexos, com predomínio em caucasianos e com média de idade de início dos sintomas em torno de $40 \operatorname{anos}^{(3)}$.

\begin{abstract}
The Wegener's granulomatosis is a systemic angiitis of small and medium caliber vessels. Normally, it is characterized by the formation of granulomas with necrosis in the respiratory system and necrosing glomerulonephritis. Even though it is more common in the upper respiratory system, in the lung and in the kidney, a great range of manifestation in other different organs and tissues can be described. We report the case of a patient who, in parallel with the typical symptoms of this disease, developed some rare alteration such as the parotiditis and the hypertrophic pachymeningitis. In face of serious situations, severe disease, atypical or non responsive to conventional treatments, it is necessary a more detailed study of the case and the use of new therapeutic drugs.
\end{abstract}

Keywords: Wegener's granulomatosis, parotiditis, hipertrophic pachymeningitis.

Embora possa atingir os mais diferentes órgãos e tecidos, o seu acometimento é classicamente descrito no trato respiratório superior, pulmões e rins.

Os sintomas do trato respiratório superior estão presentes em 90\% a 95\% dos casos e incluem rinorréia, secreção nasal purulenta ou sangüinolenta, sinusite, úlceras nasais e orais, rouquidão, mastoidite, otalgia, otorréia e alterações auditivas $^{(1-4)}$. Como estes sintomas são muito comuns, freqüentemente são abordados como infecção ou alergia, até que a doença de base seja revelada ${ }^{(3)}$. Os sintomas do

\footnotetext{
* Serviço de Reumatologia da Santa Casa de Belo Horizonte, MG. Recebido em 10/07/2003. Aprovado, após revisão, em 04/03/2004.

1. Médica assistente e preceptora da residência médica do serviço de Reumatologia da Santa Casa de Belo Horizonte, MG.

2. Médico residente do serviço de Reumatologia da Santa Casa de Belo Horizonte, MG.

. Médica residente do serviço de Reumatologia da Santa Casa de Belo Horizonte, MG.

4. Médico assistente e preceptor da residência médica do serviço de Reumatologia da Santa Casa de Belo Horizonte, MG.

5. Médica assistente e preceptora da residência médica do serviço de Reumatologia da Santa Casa de Belo Horizonte, MG.

6. Chefe do serviço de Reumatologia da Santa Casa de Belo Horizonte, MG.

Endereço para correspondência: Ana Paula Monteiro Gomides. Santa Casa de Misericórdia de Belo Horizonte, MG, R. Francisco Sales 1.111, Santa Efigênia, Belo Horizonte, MG, CEP 30150-221. E-mail: anapmgomides@ig.com.br
} 
trato respiratório inferior, também com prevalência de $90 \%$ a 95\%, incluem tosse, hemoptise, dispnéia e pleurite, além da presença de nódulos e infiltrados pulmonares ${ }^{(1-4)}$.

O envolvimento renal ocorre em até 75\% dos pacientes ao longo da evolução e é caracterizado por uma glomerulonefrite, podendo decorrer insuficiência renal ${ }^{(3)}$.

Sintomas gerais como febre, perda de peso, mal-estar, anorexia e fadiga, embora inespecíficos, são muito comuns ${ }^{(1-3)}$.

As manifestações musculoesqueléticas são freqüentes $\mathrm{e}$ variadas, mas as mais comuns são artralgias e mialgias. Pode haver quadros de monoartrite ou de poliartrite simétrica semelhante à artrite reumatóide ${ }^{(3-4)}$.

As alterações oculares estão presentes em $50 \%$ a $60 \%$ dos pacientes ${ }^{(2-4)}$. A proptose ocular, muito característica, deve-se ao crescimento de granuloma retro-orbitário ${ }^{(5)}$, processo infeccioso geralmente doloroso e que pode provocar diplopia ou perda visual. Outras alterações encontradas são conjuntivite, episclerite, uveíte, úlceras de córnea e vasculite retiniana.

As manifestações neurológicas são observadas em em 20\% a $25 \%$ dos casos, sendo a mononeurite múltipla a mais comum $^{(2-4)}$. Entretanto, várias outras podem ocorrer, como neuropatia craniana, hemorragia cerebral, cerebrite, diabetes insipidus e a paquimeningite hipertrófica.

Alterações cutâneas como nódulos subcutâneos, púrpura palpável e úlceras são encontradas em $40 \%$ a $50 \%{ }^{(2-4)}$.

Manifestações cardíacas como pericardite e pancardite aparecem em aproximadamente $20 \%$ e alterações gastrintestinais como hepatite e vasculite intestinal em cerca de $15 \%\left({ }^{(3)}\right.$.

Raramente a GW afeta as parótidas, mama, uretra, vagina, próstata, testículos, artéria pulmonar e linfonodos ${ }^{(3)}$.

A tríade clássica anatomopatológica compreende granulomas com necrose nas vias aéreas, vasculite necrotizante ou granulomas em artérias de pequeno calibre e glomerulonefrite necrotizante segmentar e focal ${ }^{(4)}$.

O prognóstico sem tratamento é extremamente grave, com relato de sobrevida média de cinco meses em $1958^{(4)}$. Atualmente, com o tratamento adequado, o prognóstico melhora sensivelmente, com sobrevida média de $80 \%$ em dez $\operatorname{anos}^{(4)}$. A morbidade também é marcante, principalmente considerando-se insuficiência renal, perda auditiva e visual, deformidade nasal e estenose de traquéia( ${ }^{(2)}$.

Com a terapêutica adequada há melhora em 90\% e remissão em $75 \%$ dos $\operatorname{casos}^{(2,6)}$. Entretanto, recidivas são freqüentes, ocorrendo em até $50 \%$ dos pacientes que entraram em remissão. O tratamento padrão é feito com corticóide e ciclofosfamida orais ${ }^{(2,4-6)}$. Muitas vezes são necessários pulsos de metilprednisolona e ciclofosfamida venosos. Alternativas terapêuticas incluem metotrexate, imunoglobulina IV, anti TNF $\alpha$, sulfametoxazol-trimetoprim, ciclosporina, azatioprina e micofenolato mofetil ${ }^{(2,6)}$.

\section{RELATO DE CASO}

Paciente SMO, 30 anos, masculino, lavrador, foi internado em outubro de 2002 na Santa Casa de Belo Horizonte, MG, com quadro de dois meses de evolução de hipoacusia bilateral, rinorréia, otorréia, prostração intensa e emagrecimento de $10 \mathrm{~kg}$. Após um mês evoluiu com cefaléia e paralisia facial periférica bilateral. Antes da internação foi tratado com vários esquemas de antibióticos para sinusite, sem resposta.

Ao exame físico, apresentava-se emagrecido, adinâmico, com paralisia facial periférica bilateral. $\mathrm{Na}$ ausculta respiratória havia diminuição do murmúrio vesicular na base direita. Exames complementares revelaram: hemograma, urina rotina, hemoculturas, função renal e íons normais; anti HIV:negativo, VHS:103mm/1h, PCR $<6 \mathrm{mg} / \mathrm{dL}$. TC crânio mostrou uma sinusite etmoidoesfenomaxilar aguda e otomastoidite bilateral. TC de seios da face revelou uma pansinusite crônica com sinais de agudização. Liquor normal. Audiometria demonstrou surdez neurossensorial bilateral; pANCA: negativo e cANCA positivo 1:80. Biópsia de septo e mucosa nasais (duas amostras): processo inflamatório em atividade com granulomas e sinais de vasculite com pesquisa negativa para fungos, BAAR e parasitos (Figura 1). Radiografia e TC do tórax evidenciaram imagem de consolidação com cavitações no seu interior no lobo inferior do pulmão direito.

Durante a internação evoluiu com dor e aumento no volume da parótida esquerda. Realizou-se US de parótidas, que sugeriu processo inflamatório agudo, confirmado por punção aspirativa. Foi iniciada antibioticoterapia e posteriormente pulsoterapia mista (metilpredinisolona e ciclofosfamida), seguida de prednisona $60 \mathrm{mg} / \mathrm{dia}$. Em função da intensidade das manifestações clínicas e do significativo comprometimento do estado geral, foi mantido o esquema de pulsoterapia mista mensal.

Após dois meses do início do tratamento, houve melhora importante da paralisia facial e da parotidite. Entretanto, apresentava rinorréia piossangüinolenta, tosse produtiva, cefaléia incapacitante e proptose progressiva no olho direito. Realizou radiografia do tórax, que evidenciou aumento na área de consolidação do lobo inferior direito. Radiografia dos seios da face revelou níveis hidroaéreos nos seios 
maxilares. Nova TC dos seios da face evidenciou sinusite, massa retro-orbitária direita em contigüidade com os músculos reto medial, reto superior e elevador da pálpebra (Figura 2). Iniciado novo ciclo de antibioticoterapia e indicado procedimento cirúrgico em função da piora da proptose e acometimento de musculatura ocular. Realizada frontoetmoidectomia externa bilateral, com retirada parcial da massa retro orbitária. Material cirúrgico foi enviado para biópsia com histologia compatível com granulomatose de Wegener.

O paciente evoluiu com piora da cefaléia holocraniana, sem resposta a diferentes esquemas analgésicos (morfina em dose elevadas, analgésicos comuns, carbamazepina, amitriptilina e AINES). Nova TC do crânio revelou pansinusite, sem alterações de parênquima cerebral. RNM de crânio evidenciou paquimeningite hipertrófica, sem lesões vasculares ou encefálicas (Figura 3). O paciente evoluiu com piora do estado geral e hipotensão. Na cultura da secreção da ferida operatória houve crescimento de Pseudomonas aeruginosa e Burkholderia cepaci sensíveis somente a meropenem. Em razão da gravidade da doença de base e da presença de processo infeccioso associado, foi iniciado tratamento com gamaglobulina humana $(2 \mathrm{~g} / \mathrm{kg} /$ dose-3 dias). Após estas medidas o paciente evoluiu com melhora importante e progressiva do estado geral e da cefaléia. Foram suspensos rapidamente os

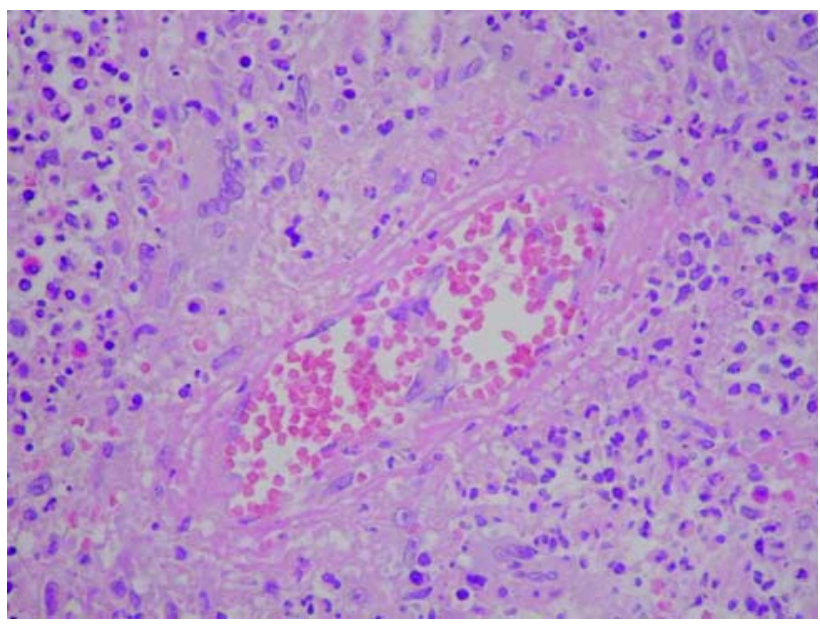

Figura 1 - Corte histológico de biópsia do septo nasal mostrando granuloma com infiltrado inflamatório neutrofílico e presença de células gigantes, necrose fibrinóide, vaso de pequeno calibre com inflamação e necrose de sua parede. analgésicos e antibióticos, com boa resposta. Recebeu alta hospitalar em uso de corticoterapia, ciclofosfamida oral (3mg/ $\mathrm{kg} /$ dose) e sulfametoxazol-trimetoprin.

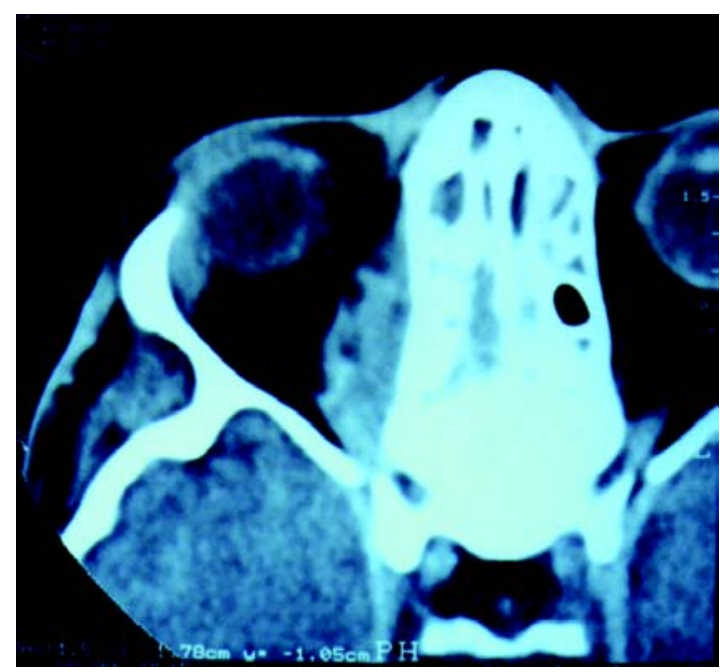

FigURA 2 - TC dos seios da face mostrando granuloma retroorbitário com proptose ocular.

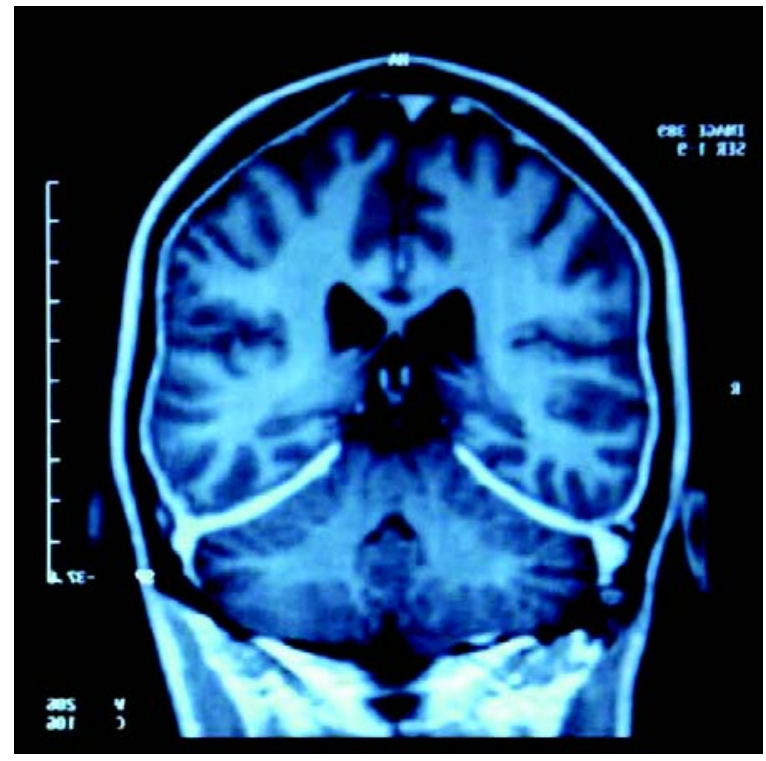

FiguRA 3 - Ressonância magnética de encéfalo, mostrando captação exuberante do contraste e espessamento da dura-máter compativel com uma paquimeningite hipertrófica. 


\section{DISCUSSÃO}

Descrevemos um caso de granulomatose de Wegener com várias manifestações típicas da doença, como sinusite recorrente, proptose e lesão pulmonar, além de surdez e paralisia facial. A presença do anticorpo C-ANCA e a biópsia de vários sítios afetados confirmaram a suspeita clínica. Durante a evolução constatamos algumas manifestações raras da doença como parotidite e paquimeningite.

O acometimento de glândulas salivares é uma manifestação incomum e pode ocorrer como inflamação de glândulas submandibulares e/ou parótidas ${ }^{(8,14)}$. Alguns casos já foram descritos e geralmente são associados às formas limitadas ${ }^{(8-14)}$. Tal manifestação pode estar presente na apresentação inicial e geralmente regride com a corticoterapia e tratamento imunossupressor para a doença de base $^{(10,13)}$.

O comprometimento neurológico na GW tem sido descrito nas formas limitadas e difusas da doença em porcentagens que variam de $22 \%$ a $54 \%^{(7)}$. Várias manifestações têm sido descritas, sendo a mais comum a neuropatia periférica (especialmente a mononeurite múltipla), mas também a neuropatia craniana, eventos cerebrovasculares e convulsões ${ }^{(15)}$.

A afecção meníngea é uma manifestação rara, com poucos casos descritos na literatura ${ }^{(16-18)}$. Vários mecanismos têm sido propostos na sua patogenia como vasculite, inflamação granulomatosa da meninge e contigüidade de lesões

\section{REFERÊNCIAS}

1. Rose BD, King TE, Hoffman GS: Clinical manifestations and diagnosis of Wegener's granulomatosis and microscopic polyangiitis. UpToDate 10.1, Wellesley MA-EUA, 2002.

2. Bennet JC, Plum F: Cecil Tratado de Medicina Interna, 20.a ed, Guanabara Koogan, 1997.

3. Klippel JH, Dieppe PA: Rheumatology, vol. 2, 2nd ed, Mosby International, 1998.

4. Lhote F, Guillevin G: Vascularites et désordres apparentés. Encyclopédie Médico-Chirurgicale (Elsevier, Paris-France), Appareil locomoteur 14-245-F10, 1994, 14p.

5. Moreira C, Carvalho MAP: Reumatologia: Diagnóstico e Tratamento, 2.a ed, Medsi, 2001.

6. Rose BD, Appel GB, Kaplan AA, Hoffman GS: Treatment of Wegener's granulomatosis and microscopic polyangiitis. UpToDate 10.1, Wellesley MA-EUA, 2002. de seios paranasais ${ }^{(7)}$. O principal sintoma é a cefaléia intensa, persistente, muitas vezes com pouca resposta aos analgésicos convencionais, assim como no caso relatado. Outros sintomas, como lesão de nervos cranianos, rigidez da nuca e hidrocefalia podem ocorrer. O estudo do líquido cefalorraquidiano pode evidenciar aumento de proteínas totais. Os exames de imagem (TC e RNM) mostram espessamento difuso da meninge e ocasionalmente nódulos, com impregnação exuberante do contraste ${ }^{(7)}$. No diagnóstico diferencial da paquimeningite devem ser consideradas outras doenças como sarcoidose, doença de Wipple, processos infecciosos (TBC, sífilis) e neoplásicos ${ }^{(19,20)}$. Até o momento não há descrição de tratamento específico para o envolvimento meníngeo da doença. Geralmente há boa resposta com corticoesteróides orais e imunossupressores. No presente caso não obtivemos melhora clínica com o uso destes medicamentos, o que ocorreu somente após administração de imunoglobulina.

O diagnóstico mais precoce e os avanços no tratamento da GW melhoraram a sobrevida nos últimos anos, muito embora alguns pacientes apresentem doença grave e refratária aos medicamentos de rotina ${ }^{(3)}$.

O caso relatado ilustra a grande morbidade da doença com acometimento multissistêmico. Neste contexto, outras opções terapêuticas, como a gamaglobulina humana, podem se apresentar como uma boa opção, particularmente em casos graves e com processo infeccioso significativo $\operatorname{associado}^{(20)}$.

7. Garcia-Asensio S, Barrena R, Guelbenzu S, Velilla J, Martinez R: Granulomatosis de Wegener con afectaciòn meningea: correlación clinicorradiológica. Rev Neurol 27:833-6, 1998.

8. Specks U, Colby TV, Olsen KD, De Reme: Salivary gland involvement in Wegener's granulomatosis. Arch Otolaryngol Head Neck Surg 117: 218-23, 1991.

9. Ah-See KW, Mc Laren K, Maran AG: Wegener's granulomatosis presenting as major salivary gland enlargement. J Laryngol Otol 110:691-3, 1996.

10. Vanhauwaert BG, Roskams TA, Vanneste SB, Knockaert DC: Salivary gland involvement as inicial presentation of Wegener's disease. Postgrad Med J 69:643-5, 1993.

11. Murty GE, Mains BT, Bennet MK: Salivary gland involvement Wegener's granulomatosis. J Laryngol Otol 104:259-61, 1990.

12. Lustmam J, Segal N, Markitiziu A: Salivary gland involvement in Wegener's granulomatisis. A case report and review of literature. Oral Surg Oral Med Oral Pathol 77:254-9, 1994. 
13. Berge S, Niederhagen B, Von Lindern JJ, Appel T, Reich RH: Salivary gland involvement as an inicial presentation of Wegener's disease. Int J Oral Maxillofac Surg 29: 450-2, 2000.

14. Liu SY, Vlantis AC, Lee WC: Bilateral parotid and submandibular glan enlargement: rare features of Wegener's granulomatosis. J Laryngol Otol 117:148-50, 2003.

15. Nishino H, Rubino FA, Deremee RA, Swanson JW, Parisi JE: Neurological involvement in Granulomatosis - an analysis of 324 consecutive patients at the Mayo Clinic. Ann Neurol 33: 4-9, 1993.

16. Akihiro K, Kan K, Hayabusa N, et al: A case report of Wegener's granulomatosis with Hipertrophic Pachymeningtis. Practica OtoRhino-Laryingologica 95:11, 2002.
17. Barrell HC, McCorochie NS: Pachymeningitis in Wegener's granulomatosis. Pediatric Neonatal 15:352-6,1998.

18. Czarmecki E, Spickler E: Granulomatosis de Wegener con afectación meníngea. Neurology 43:1329-34, 1993.

19. Finsterer J, Kladosek A, Áustria V, et al: Chronic Granulomatosus Meningitis with multiple cranial nerve lesions, hydrocephalus, stroke, sinus trombose and epilepsy. South Med J 93:1108-11, 2000.

20. Jayne DR, Chapel H, O' Donoghue D, Scott D, et al: Intravenous immunoglobulin por ANCA associated systemic vasculitis with persistent disease activity. QJM 93:433-9, 2000. 